\title{
Sensing strain and damage in polyurethane-MWCNT nano-composite foams using electrical measurements
}

\author{
A. Baltopoulos, N. Athanasopoulos, I. Fotiou, A. Vavouliotis, V. Kostopoulos* \\ Applied Mechanics Laboratory, Department of Mechanical Engineering and Aeronautics, University of Patras, \\ GR 265 04, Rio - Patras, Greece
}

Received 30 May 2012; accepted in revised form 19 August 2012

\begin{abstract}
This work deals with the damage identification in polymeric foams through the monitoring of the electrical resistance of the system. To assess this idea electrically conductive rigid Poly-Urethane (PUR) foams at various densities were prepared. Multi-Wall Carbon Nanotubes (MWCNT) were dispersed in the host polymer at various concentrations through high shear mixing to provide electrical conductivity to the system. The PUR/MWCNT foams exhibited varying electrical conductivity on a wide range of densities and nano-filler contents. The prepared foams were subject to compression tests. Electrical resistance was recorded online during the tests to monitor the change of the bulk property of the materials. A structural-electrical cross-property relation was exhibited. The distinctive phases of foam compression were successfully identified from the electrical resistance profile recorded during the tests. A characteristic master curve of the change of electrical resistivity with respect to load and damage is proposed and analyzed. It was shown that the found electrical resistance profile is a characteristic of all the MWCNT contents and depends on density and conductivity. MWCNT content contributes mainly to the sensitivity of electrical sensing in the initial stage of compression. Later compression stages are dominated by foam microstructural damage which mask any effect of CNT dispersion. Micro-structural observations were employed to verify the experimental findings and curves.
\end{abstract}

Keywords: smart polymers, nano-composite foams, electrical conductivity, damage mechanism sensing

\section{Introduction}

The addition of carbon nano-fillers (nanofibers (CNF), nanotubes (CNT) etc.) into plastics has been shown to affect the various properties of the resulting material and effectively increase the electrical conductivity of the system by several orders of magnitude [1]. This is attributed to the formation of a conductive network of the conductive nanofillers, which can be described as a percolated network. The increased electrical conductivity of the nano-reinforced materials has given rise to their use in various applications [2].

Polymeric foams (e.g. Rigid PolyUrethane (PUR)) represent a very interesting and useful sub-group, finding vast range of applications due to their versatility. In structural applications, they are commonly used due to the weight saving capabilities they can offer in the design (e.g. as sandwich cores).

Combining nano-fillers with foam materials, nanoreinforcement of foams has been developed and studied the past decade, but mainly focused on the mechanical and thermal properties. Electrical conductivity of nano-composite foams is much less studied. Works on the electrical properties of nanoreinforced polymeric foams are rather sporadic [310]. The relationship between the resulting electrical conductivity and the density of the rigid foams for given CNT concentrations was reported in [6] but only recently described further [10].

\footnotetext{
${ }^{*}$ Corresponding author, e-mail: kostopoulos@mech.upatras.gr (C) BME-PT
} 
The advantage electrical properties can offer is the capability to utilize self-sensing concepts for monitoring strain and/or damage [11]. Electrical resistance change method has been successfully employed as a health monitoring technique to follow strain and internal damages evolution in composite materials. It has successfully been applied on nano-composite polymers [12-15], on carbon fibre reinforced plastics (CFRP) [16-20] and in glass fibre reinforced plastics (GFRP) with conductive additives to increase matrix electrical conductivity (e.g. carbon nanotubes [21-23]). Attempts to model the electrical sensing and piezo-resistive response of the materials have also been reported [12, 13, 15, 24]. Even for Silicone-Carbide based ceramic matrix composites online monitoring of damage accumulation was achieved by measuring electrical properties [25]. Furthermore, cross-property relations between electric and elastic properties for metal foams have been developed in [26] for direct definition of elastic properties from electrical measurements.

The use of the electric field has been proposed and demonstrated to perform very well in defining various other properties. For example, electrical measurements have been used to monitor the foaming process and polymerization of polymeric foams [27] while dielectric measurements have been used for measuring the density of polymer foams [28]. Brady et al. [29] developed electrically conductive poly-pyrrole coated PUR foam. The conductance of the foam was found to change linearly with the compressive load applied; single and repeated. For aluminium foams, Kim et al. [30] developed a set of mathematical relationships based on experimental data to obtain mechanical properties (elastic modulus, compressive strength, densification strain) using electrical conductivity as a Non-Destructive Inspection method.

Xiang et al. [9] developed electrically conductive PUR foams ( $1 \mathrm{wt} \%$ CNT content and density between $200-550 \mathrm{~kg} / \mathrm{m}^{3}$ ) and studied the temperature dependence of the electrical resistivity of the foam, ultimately utilizing this dependence for sensing. They showed that the foams exhibited a consistent and repeatable negative temperature coefficient of resistivity. The reduction of the cell walls' thickness causes the decrease in the distance between adjacent CNTs. The authors noted that the nearer and straighter CNTs, accordingly, create more effective conductive paths within the matrix, which readily permit charge to transport, resulting in the decrease in the volume resistivity.

Based on the available literature, it is made obvious that potential synergies between electrical properties and nano-composite foams remain rather unexplored. In this work, we investigate the use of electrical measurements for strain sensing and eventually damage monitoring in nano-composite foams. For this purpose, PUR foams having different MultiWall CNT (MWCNT) concentrations and different densities were developed. The developed threephase material (polymer, MWCNT and $\mathrm{CO}_{2}$ ) exhibited varying electrical properties with respect to the microstructure variables. The DC electrical conductivity of the various foams was studied under quasistatic compression loading. Continuous electrical recordings during the compression tests were investigated and compared against the stress state of the material. The deformation and damage evolution in foamed polymers from a micro-structural point of view was studied in comparison to the recorded electrical measurements. Identifying the loading and damage state of the foam with the proposed method could provide a novel tool for strain and damage monitoring of foams in composite structures.

\section{Materials and experimental setup 2.1. Materials and manufacturing}

A two-component PUR system from R\&G Faserverbundverkstoffe $\mathrm{GmbH}$ (Waldenbuch, Germany) was used in this study as the polymer host matrix. The A component of the system is the polyol mixture (under the commercial name of Rigid PUR foam, Product code: 170090). The B component is a 4,4'-diphenylmethane diisocyanate mixture (under the commercial name PUR Hardener 1000, Product code: 170105-2011) suitable for the production of polyurethane foam. Foaming of the material is achieved by the $\mathrm{CO}_{2}$ gas product of the chemical reaction. The bulk polymer density is $\sim 1200 \mathrm{~kg} / \mathrm{m}^{3}$. MWCNT produced by catalyzed CVD were supplied by Arkema (France). According to the manufacturer, their diameters were $10-15 \mathrm{~nm}$ and they were more than $500 \mathrm{~nm}$ long, resulting in an aspect ratio (AR) in the range of 35-50. Previous studies $[19,31,32]$ utilizing the same batch of CNTs showed good mechanical and electrical results for polymer composites. Therefore the same procedure was fol- 
lowed and the nanotubes were used as received, i.e. no treatment or functionalization took place. To eliminate any humidity present, prior to use the nanotubes were placed in an oven at $60^{\circ} \mathrm{C}$ overnight. High-shear mixing approach successfully exhibited and investigated in other studies [10, 31, 32] was used to incorporate the nano-fillers. The processing steps are illustrated in Figure 1. MWCNT were dispersed in the A component of the PUR system using high-shear mixing dissolver device (under the commercial name DISPERMAT ${ }^{\circledR}$ ) by VMA Getzmann $\mathrm{GmbH}$ (Reichshof, Germany). A rotating disk introduces shear forces to the mixture creating a vortex flow (doughnut effect). The vortex flow leads to a continuous mixing of the compound. The shear forces disentangle the CNT and reduce their agglomerates. Indications have been that dissolver shear mixing has minor effect on the characteristics of the MWCNT (e.g. CNT length) [31, 33]. The duration of mixing was $6 \mathrm{hrs}$ at $2500 \mathrm{rpm}$ and was chosen based on previous experience $[31,32]$ and initial trials [10]. The temperature of the mixture was monitored throughout the process. Mixing was performed under controlled temperature between $45-60^{\circ} \mathrm{C}$ using the double wall container of the dissolver. Water of controlled temperature ran through the mantle. Once the dispersion was prepared, the hardener was added to the mixture at a ratio of 100:144 (A:B) according to the supplier (Figure $1-$ Step2). The whole mixture was then mechanically stirred for $30 \mathrm{sec}$, until the foaming reaction was noticeable. The mixture was poured in a stainless steel mould which was hermetically sealed (Figure 1 Step3). The mould was placed in a press and was kept there to cure at room temperature for $24 \mathrm{hrs}$ followed by a post-curing phase for $4 \mathrm{hrs}$ at $50^{\circ} \mathrm{C}$.

After complete curing cycle had finished, the foamed material was de-moulded. The result of the moulding process was a rectangular foam plate $200 \times 100 \times$ $30 \mathrm{~mm}^{3}$ (Figure $1-$ Step4). From each plate the required specimens were cut using a microtome. To avoid any surface anomalies which would affect the electrical measurement, each specimen was then grinded sequentially using 4 different levels of sand-
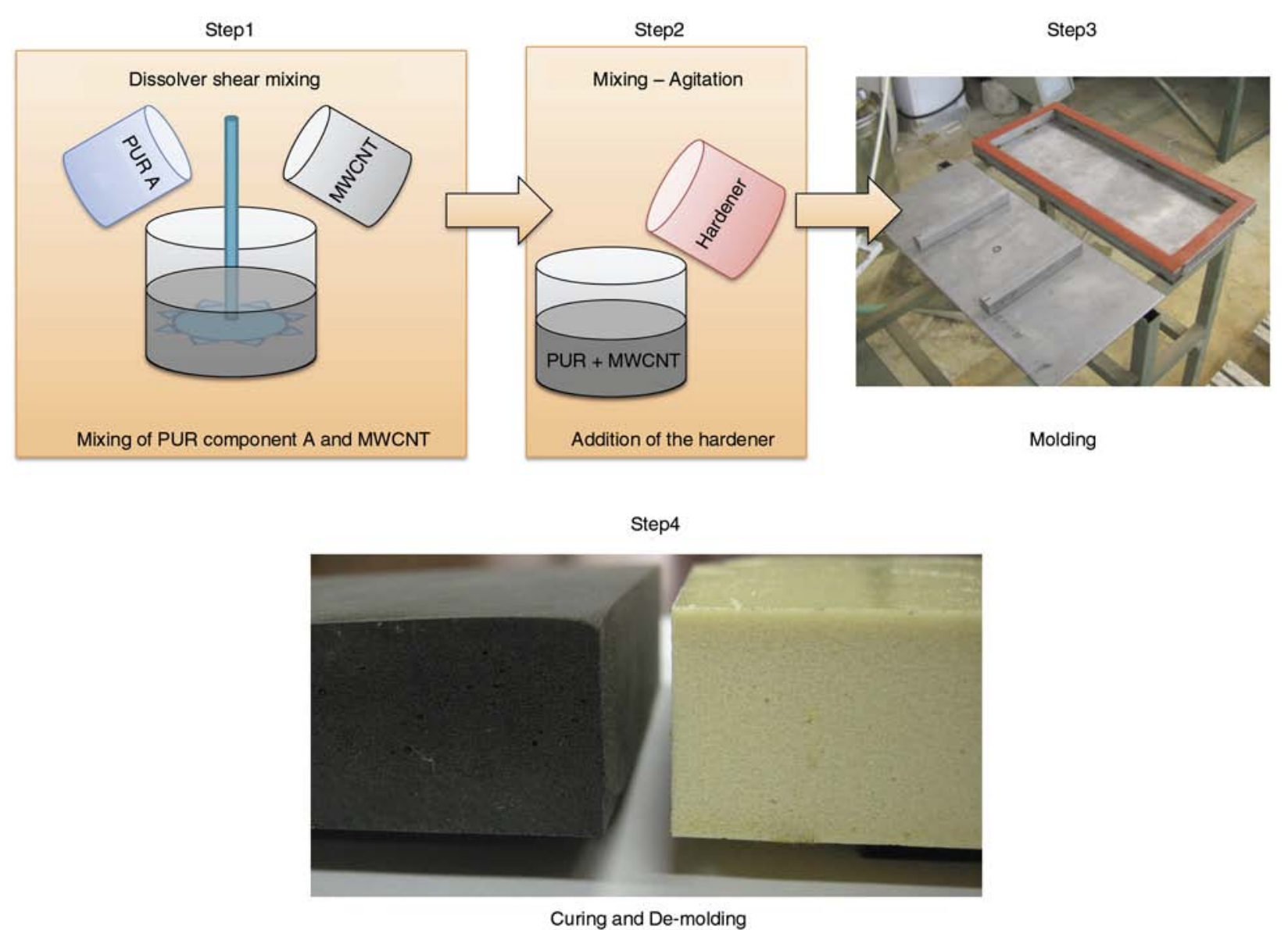

Figure 1. Nano-composite foam preparation process: Step1 - Shear mixing of MWCNT in polyol component, Step2 Addition of the hardener to the mixture, Step3 - Molding, Step4 - Curing and de-molding: Neat (right) and MWCNT (left) foam 
Table 1. Materials prepared for the study

\begin{tabular}{|l|c|c|}
\hline \multicolumn{1}{|c|}{ Group name } & Density group 1 & Density group 2 \\
\hline Lensity & $250-300 \mathrm{~kg} / \mathrm{m}^{3}$ & $350-400 \mathrm{~kg} / \mathrm{m}^{3}$ \\
\hline \multirow{2}{*}{ MWCNT content } & $3 \%$ & $2 \%$ \\
(weight per cent) & $5 \%$ & $3 \%$ \\
& & $5 \%$ \\
\hline
\end{tabular}

paper $(500,1000,2000$ and 4000) on all sides. After this, the density of each specimen was calculated by measuring the dimensions and the weight of each specimen. In principle, two foam density ranges were targeted; $250-300 \mathrm{~kg} / \mathrm{m}^{3}(20-25 \%$ relative density) and $350-400 \mathrm{~kg} / \mathrm{m}^{3}$ (30-35\% relative density). Nevertheless, foams having various different densities were produced. For convenience, the first group of densities will be referred to as Light Foam, while the second one as Dense Foam.

Two MWCNT concentrations per weight were chosen to be studied; $3 \%$ and $5 \%$. For the higher density, $2 \mathrm{wt} \%$ MWCNT was also investigated. These values correspond to the weight percentage of the CNT to the polymer and CNT mixture. The materials developed and studied in this work are summarized in Table 1.

\subsection{Experimental testing}

Compression tests were carried out according to ASTM-C365. Square specimens were cut from each plate having $25 \mathrm{~mm}$ sides and $10 \mathrm{~mm}$ thickness. The thickness direction coincided with the thickness direction of the initial rectangular foam plate. Compression was performed using an INSTRON 8872 (Norwood, USA) servo-hydraulic universal testing machine with a crosshead displacement set at $0.4 \mathrm{~mm} / \mathrm{min}$. Compression was terminated when the load reached $\sim 15 \mathrm{k} \mathrm{N}$. For each material developed (shown in Table 1) 3 specimens were tested.

Prior to any electrical measurement, following commonly reported procedures, commercially available conductive silver paint (under the commercial name RS 186-3593) supplied by RS Components Ltd (Northants, UK) was applied on the sides in contact with the electrodes (Figure 2) to minimize any contact resistance for the electrical measurements. Prior to mechanical testing, to account for any contact resistance influence to the measurements, different levels of small loads were applied to the samples at increments of $5 \mathrm{~N}$ up to $50 \mathrm{~N}$ corresponding to a maximum of $\sim 80 \mathrm{kPa}$ of pressure. For all the samples the resistance was nearly constant irrespec-

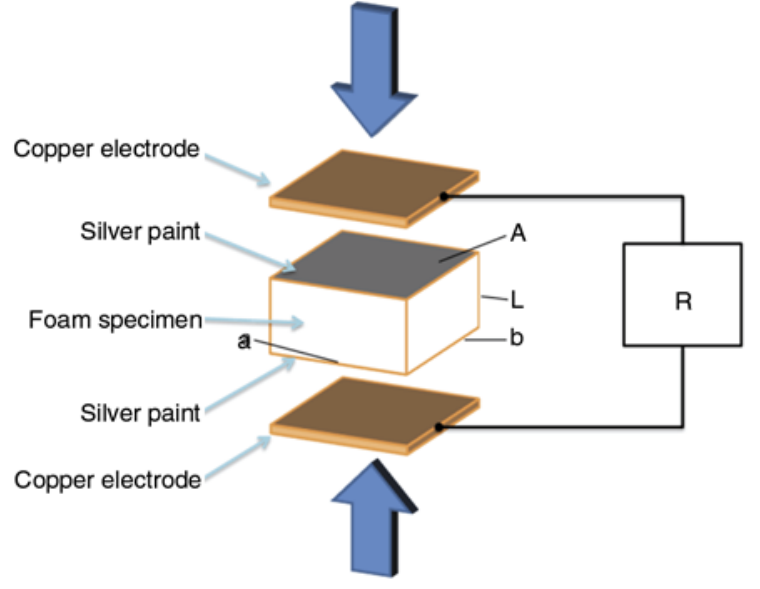

Figure 2. Exploded view of the experimental measurement configuration: electrical resistance recording during compression

tive of the applied load, indicating a good electrical contact between the electrodes and the sample.

For measuring the DC electrical resistance of the materials during the compression test (Figure 2), the silver-painted sides of the sample were placed in contact with two copper plates which served as the electrodes. A high-performance KEITHLEY 2002 digital multimeter by Keithley Instruments, Inc. (Ohio, USA) was used in a 2-probe configuration for measuring the electrical resistance. The electrical resistance of the complete system (electrodespecimen-electrode) was recorded throughout the compression test. Given the geometry of each specimen (Figure 2), the bulk volume conductivity at each instance of the test was calculated based on Equation (1):

$\sigma=\frac{L}{R A}=\frac{t}{R a b}, \quad \rho=\frac{1}{\sigma}$

where $\sigma$ is the electrical conductivity, $L$ is the length of the specimen, $A$ is the cross-sectional area of the specimen, $t$ is the thickness of the specimen, $a$ and $b$ are the cross-sectional dimensions of the specimen, $R$ is the electrical resistance measurement, and $\rho$ is the electrical resistivity. Furthermore, combining the applied compressive load on the sample and the geometric characteristics of the specimen, the pressure can be derived. For each material, five specimens were tested. All measurements were performed at room temperature.

Scanning Electron Microscopy (SEM) for microstructural and fracture characterization was performed with a LEO SUPRA 35VP by Carl Zeiss Microscopy GmbH (Jena, Germany). Different mag- 
nification levels were employed to evaluate different aspects of the materials. Low magnification was used to assess the microstructure of the foam as well as to verify the damaged microstructure after the test. Higher magnification of fractured surfaces was used to evaluate the dispersion of the CNT as well as to capture indications on the wall thickness of the microstructure.

\section{Results and discussion}

\subsection{Preparation and cellular structure}

The effective dispersion of CNT in polymers, as a research field, has attracted considerable attention due to the challenge to disentangle the agglomerates of CNT and create a homogeneous distribution throughout the host matrix. For the development of electrically conductive foams this process is also a very important step. The high shear mixing process used in this work has been shown to produce good results in dispersing the nano-fillers and developing electrically conductive polymers. At the levels of

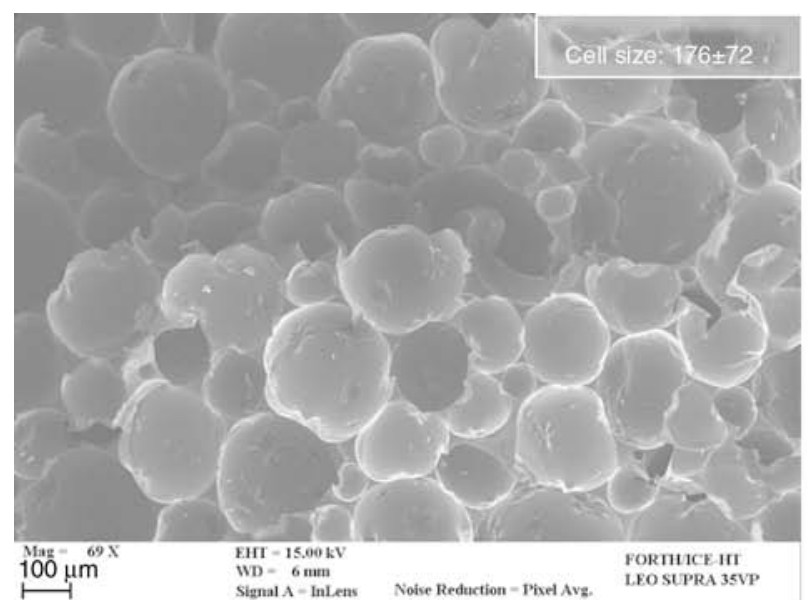

a)

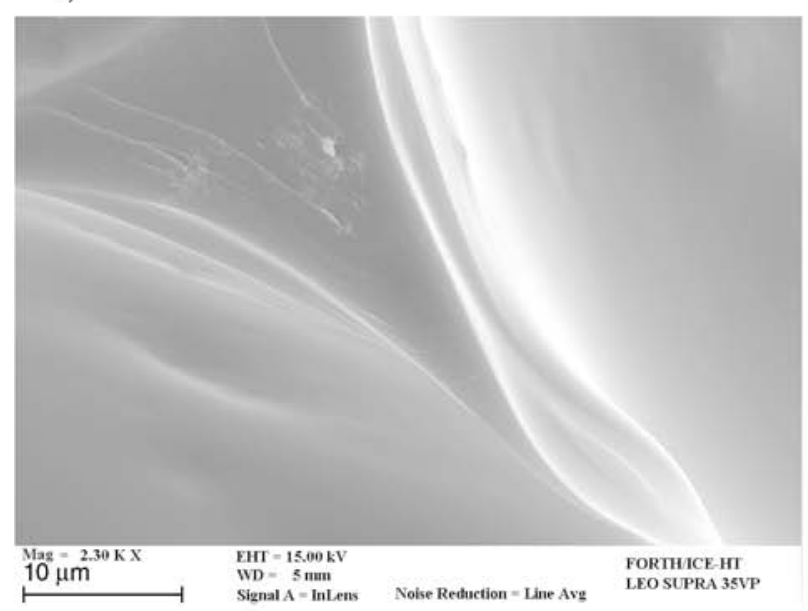

c) content investigated in this study $(>2 \mathrm{wt} \%)$ it is very difficult to avoid nano-filler agglomerations in the final polymer. Nevertheless, an initial target is to achieve relatively high electrically conductive foams.

The addition of CNT, as is commonly observed in various similar studies, has effectively increased the viscosity of the mixture (A component and CNTs), due to the extended surface interaction between the fillers and the matrix. At $5 \mathrm{wt} \% \mathrm{CNT}$ content the mixture resembled a paste, making it difficult both to handle the mixture and effectively utilizing the method to disperse the CNTs. To decrease the viscosity to a level where processing would be more effective, the temperature of the mixture was increased to $60^{\circ} \mathrm{C}$.

The developed foams are complex three-phase materials consisting of the polymer, the MWCNT and $\mathrm{CO}_{2}$ bubbles. SEM micrographs (Figure 3 and 4) provide visual evidence of the foam microstructure where the three phases are distinguishable.

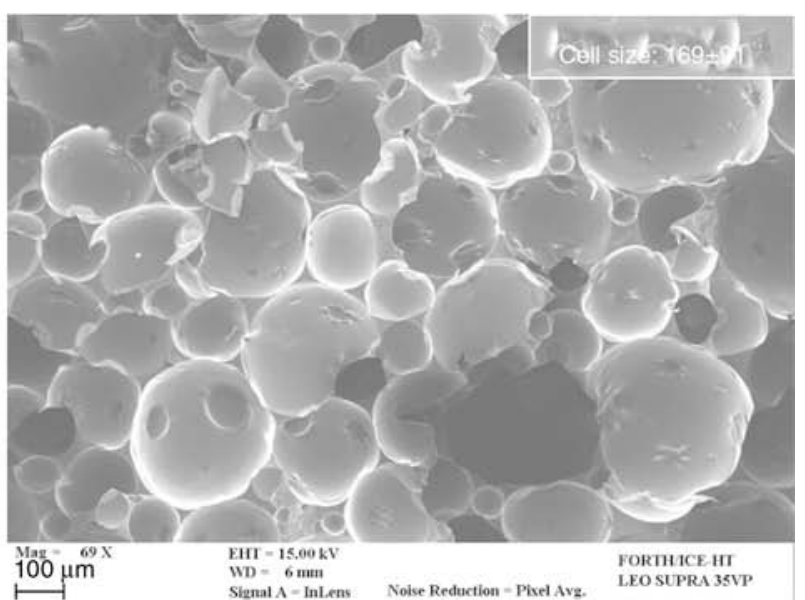

b)

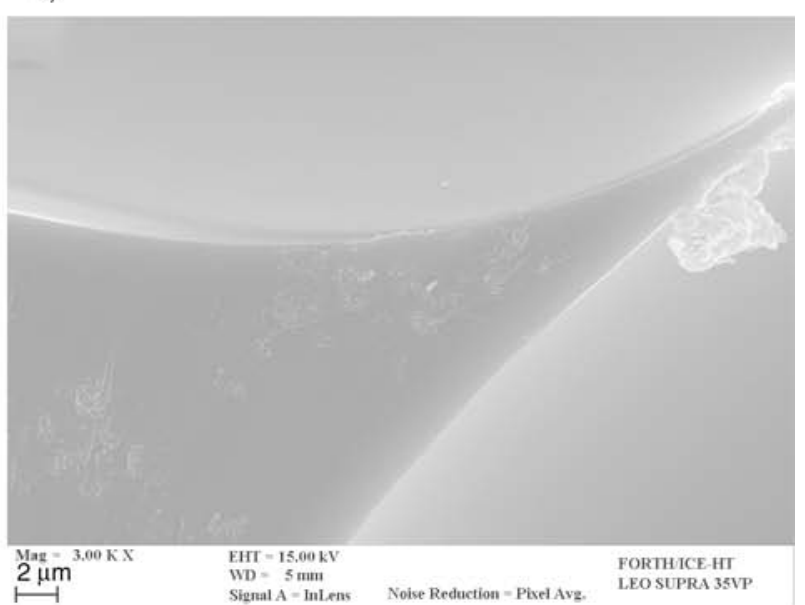

d)

Figure 3. SEM micrographs of the light nano-composite foam: (a, b) foam microstructure for 3 and 5 wt $\%$ MWCNT, (c, d) dispersion in foam for 3 and $5 \mathrm{wt} \%$ MWCNT 


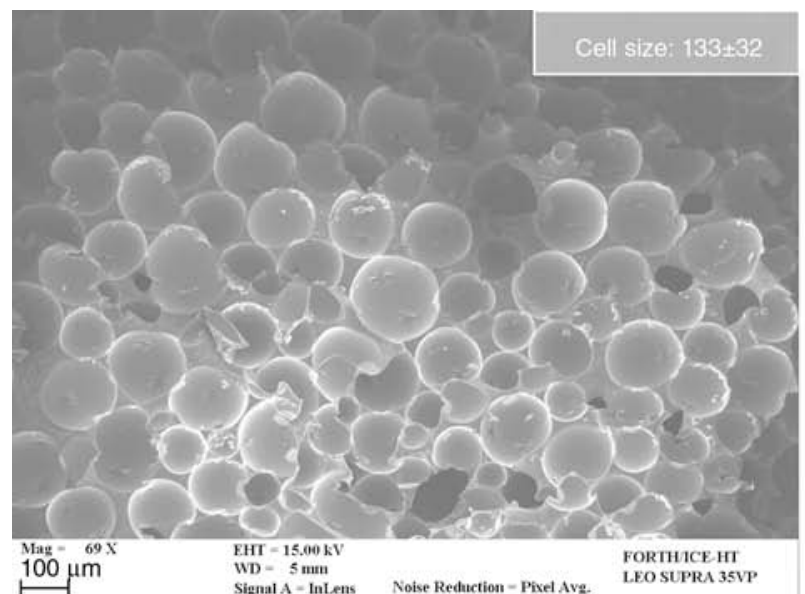

a)

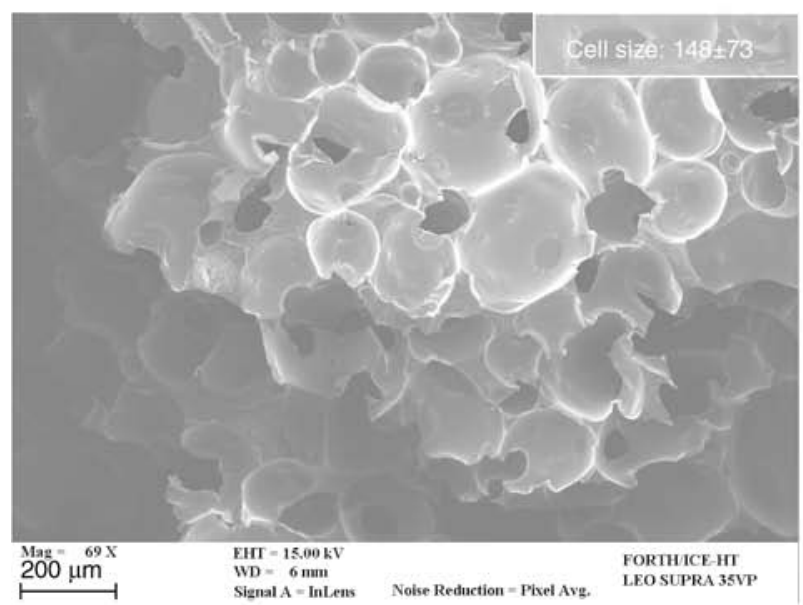

c)

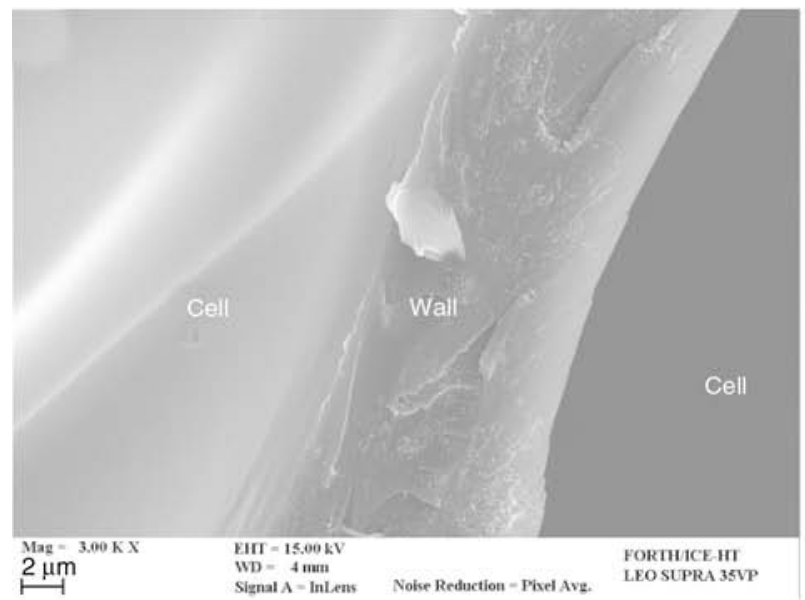

e)

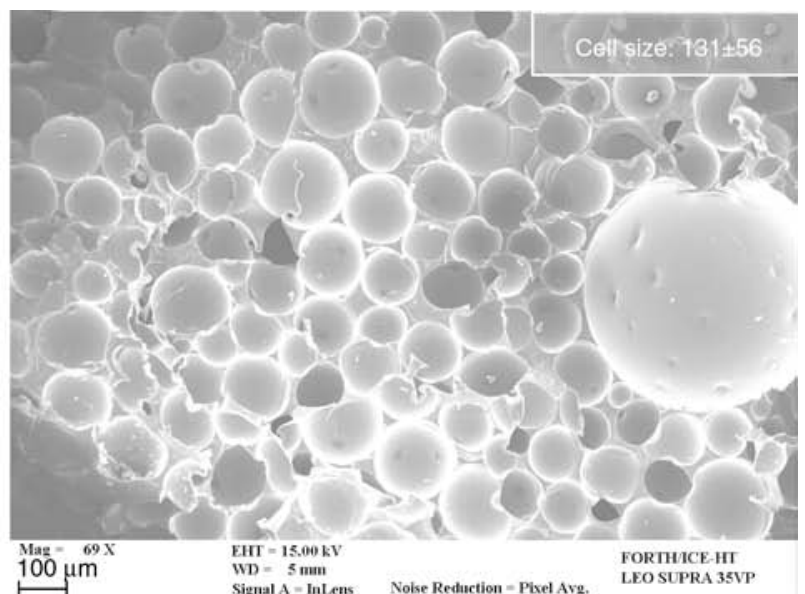

b)

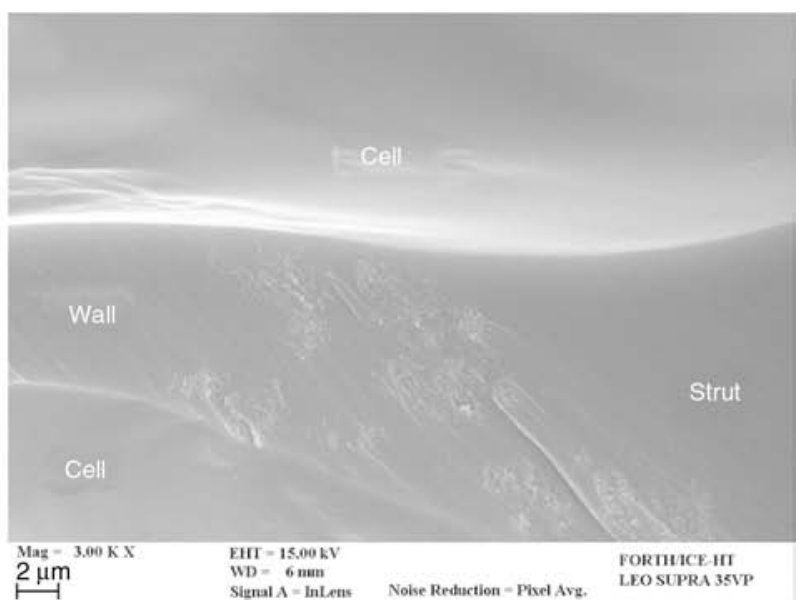

d)

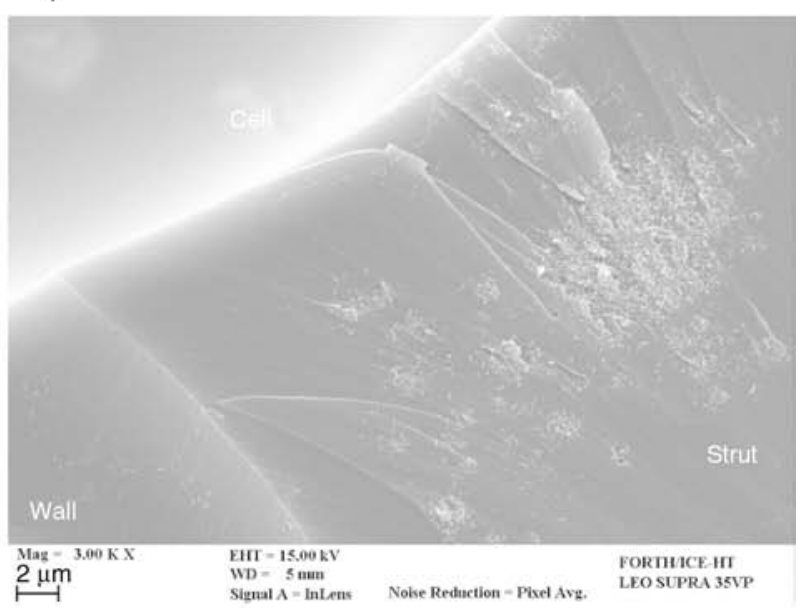

f)

Figure 4. SEM micrographs of the dense nano-composite foam microstructure: (a-c) foam microstructure for 2, 3 and 5 $\mathrm{wt} \%$ MWCNT, (d-f) dispersion in foam for 2, 3 and $5 \mathrm{wt} \%$ MWCNT

The effect of CNT on PUR foams in terms of processing and final microstructure has been investigated in a number of studies $[8,10,34,35]$. The indications are that the effect of CNT on the final microstructure is moderate and CNT do not contribute a heterogeneous nucleation factor that can change the microstructure. In this study, SEM characterization performed on the developed materials confirms these reports. The microstructure of the foams can be seen in Figure 3a, $3 b$ and Figure $4 a-4 c$ together with the elaborated values for the average cell size. The observation reveals that the addition of CNT in the mixture has practically a minor effect on the cell size for foams with similar density. The deviation of the cell size seems to increase with the addition of CNT. 
Figure $3 c, 3 d$ and Figure $4 d-4 f$ present a series of SEM micrographs focused on the strut-to-wall transition area for the different developed materials. These images provide a means to assess the achieved dispersion of CNT within the polymer. It is evident that agglomerations are present in all the cases, which is expected considering the high level of MWCNT in the polymer. In between the agglomerations individually dispersed CNT are also seen. Groups of bundled CNT form spherical structures which have a diameter in the range of $2 \mu \mathrm{m}$. For the dense foams of $5 \mathrm{wt} \% \mathrm{CNT}$, concentrated agglomerations are witnessed (Figure 4f). In the case of the light foams the thinning of the cell walls is obvious as well as the arrangement of CNT in the transition zone. CNT, either in small agglomerations or individual, are seen at the tip of the cell wall which has a thickness less than $2 \mu \mathrm{m}$ (Figure 3d). Similar indications are available for the dense foams, where a network of CNT is seen in the cell wall region (Figure $4 d$ ).

Despite the agglomerated state of CNT which decreases the effectiveness of nano-reinforcement, a conductive distribution of the CNT is achieved and has been verified by the measured electrical conductivity. The dependence of the electrical conductivity on the foaming process, the achieved micro-structure, the MWCNT content and the relative foam density has been described in [10] and is not discussed further here.

\subsection{Evolution of apparent electrical properties during mechanical compression}

As a first indication of the electrical response of the foams to mechanical load, the recorded bulk electrical resistance values during quasi-static compressive loading are presented in Figures 5 and 6 for the

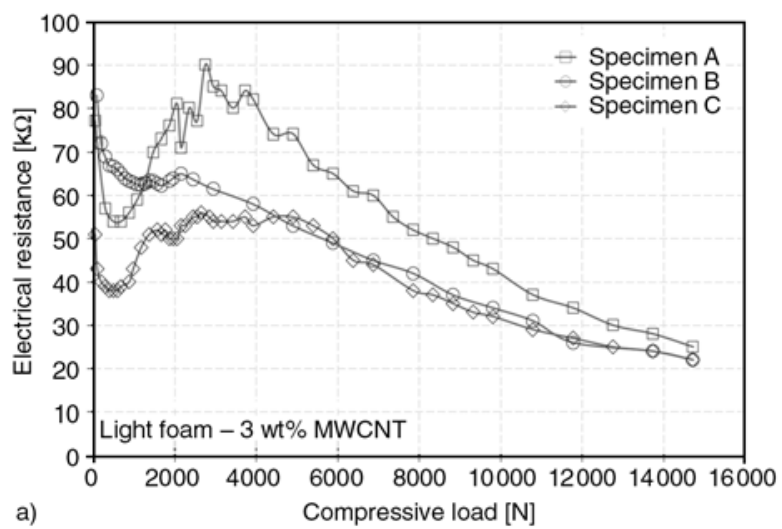

light and dense foam groups respectively. The measurements were performed in the through thickness direction as shown in Figure 2. The change of electrical resistance during loading is evident for all material groups. A general agreement between the specimens with the same physical characteristics is noted. Consistent patterns are exhibited by specimens within the same group. Furthermore the patterns present similarities among the same density groups. Repeatability of the measurements was verified for each sample prior to the test for the elastic region of the compression curve (strain $<5 \%$ ), by repeated loading-unloading.

For the light foams (Figure 5), the electrical resistance $(R)$ pattern during loading exhibits a consistent behaviour for both nano-filler contents. The response gives repeatable results for all the specimens within the same group. Minor differences within the same group are noticed in the initial part of the curve, but do not change the whole pattern. All electrical resistance curves start with an abrupt linear drop, reaching local minimum around $400-500 \mathrm{~N}$ of load. Further increase of the load, leads to an increase in $R$ until a local maximum is reached between $2-3 \mathrm{kN}$ of applied load. Increasing the applied load further, the resistance $R$ decreases monotonically until $15 \mathrm{kN}$, where the experiment was stopped. At this final phase the decreasing trend was almost linear. The initial values of the curves are all at the same range for both sets of nano-filler contents; $60-90 \mathrm{k} \Omega$ for $3 \mathrm{wt} \%$ MWCNT and $0.6-1.6 \mathrm{k} \Omega$ for the $5 \mathrm{wt} \%$ MWCNT. This difference between the two groups was expected due to the increase in the nano-filler content as verified in [10].

Figure 6 presents the recorded values for the dense foam group. The pattern for the dense foams is similar for the two lower nano-filler contents. For the

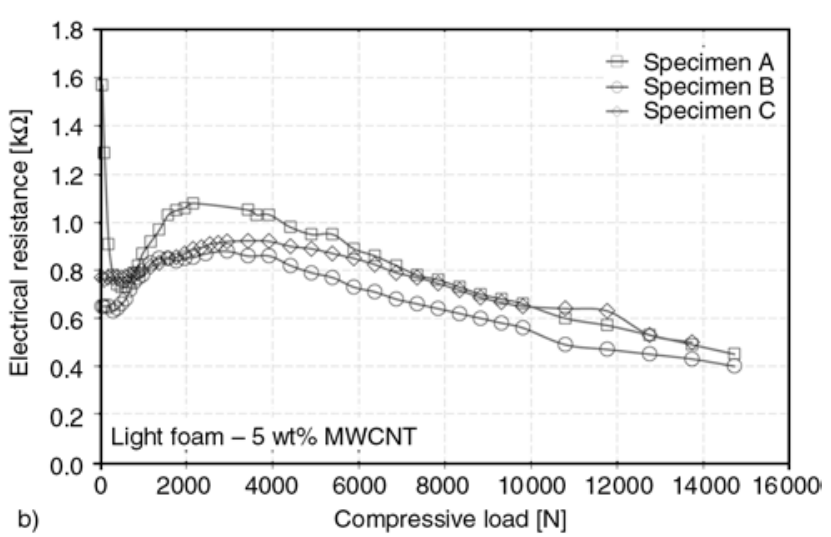

Figure 5. Electrical resistance Vs. compressive load: light foams (a) $3 \mathrm{wt} \%$, (b) $5 \mathrm{wt} \% \mathrm{MWCNT}$ 
highest content a different response is observed. All MWCNT contents exhibit an initial drop in the
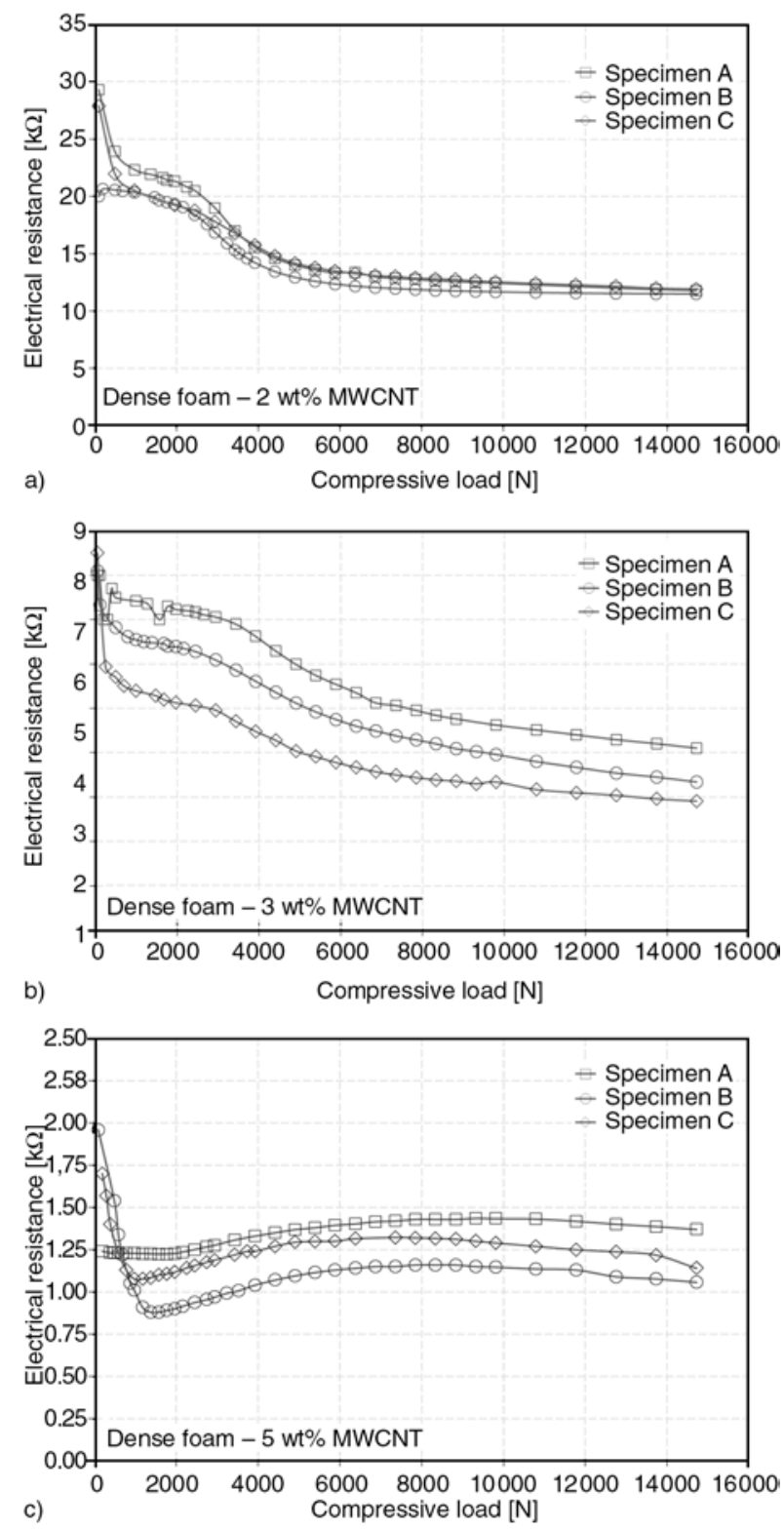

Figure 6. Electrical resistance Vs. compressive load: dense foams (a) $2 \mathrm{wt} \%$, (b) $3 \mathrm{wt} \%$, (c) $5 \mathrm{wt} \% \mathrm{MWCNT}$

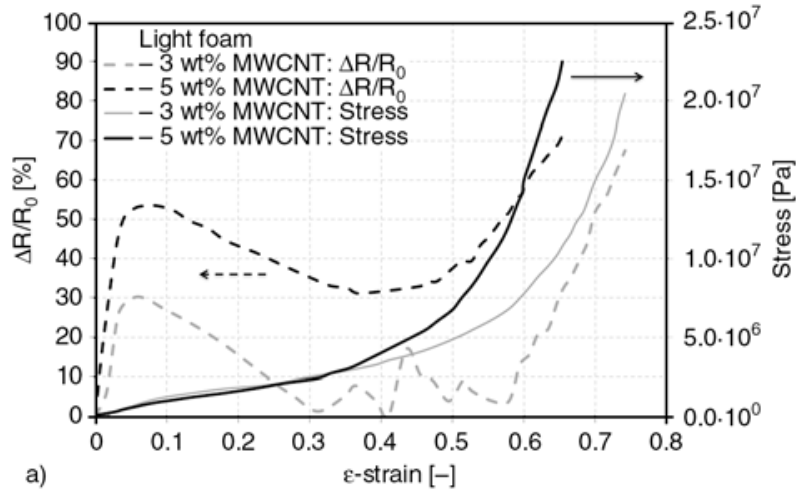

measured resistance, up to between $200-400 \mathrm{~N}$ of applied load. For the low MWCNT contents, an increase in the applied load further from $500 \mathrm{~N}$ results in a short plateau for the resistance $R$; up till $3 \mathrm{kN}$ for $2 \%$ and $4 \mathrm{kN}$ for $3 \%$. Continuing further to increase the load, an asymptotic decrease up to a final resistance value is exhibited until the load reaches $15 \mathrm{kN}$. For the $5 \mathrm{wt} \%$ MWCNT concentration, a clear intermediate plateau is not revealed. Rather a local minimum is shown, followed by an asymptotic increase in the final part of the curve. Again, the recorded response curves exhibit high repeatability among the specimens, with only minor differences in the response.

To better reveal the information within the electrical response it is useful and commonly employed to express the normalized relative values of resistance. These are presented in Figure 7 together with the stress values against derived strain, for the two density groups. The values to prepare these figures were calculated based on the recordings of the experiment, as opposed to Figure 5 and 6 where the raw data are reported.

From the mechanical point of view, the elaborated stress-strain curves follow the extensively documented behaviour of cellular solids; an initial linear increase in stress followed by an elasto-plastic yielding (called plateau region) and reaching the densification region where stress increases rapidly. It can be noted that the stress-strain curves of the nano-composite foams deviate slightly from the 'nominal' description in that the linear and plateau regions are not clearly distinct. Instead, in this region the materials show an increasing linear behaviour, which is a common observation among polymer foams [36] and indicates plastic yielding earlier than usual. Nevertheless, the difference in the slope of the two phases is noticeable.

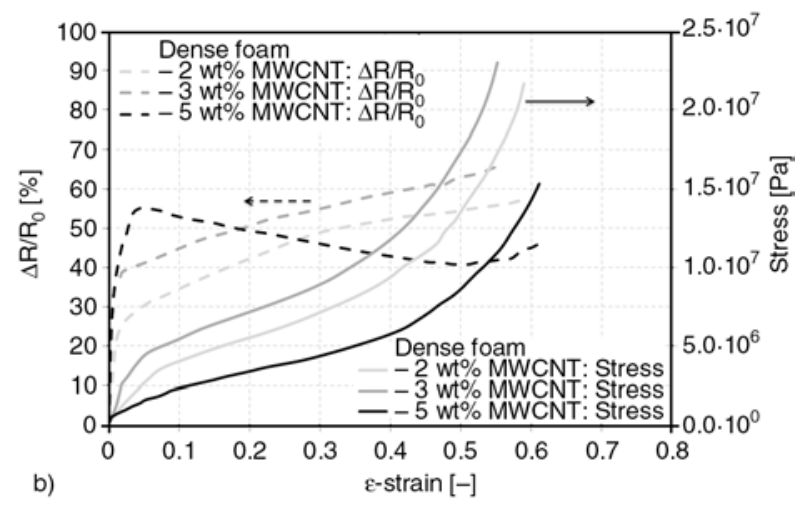

Figure 7. Stress and relative electrical resistance change $\left(\Delta R / R_{0}\right)$ Vs. strain (a) light foams, (b) dense foams 
From the perspective Figure 7 offers, the electrical response is more informative and the relation between the mechanical and electrical behaviour is becoming more evident. The effect of CNT on the mechanical behaviour of the foams is also visible in the same diagram, which can directly be taken into account in the electrical response evaluation.

For the light foams, starting from non-strained foams, $\Delta R / R_{0}$ increases linearly up to nearly $5 \%$ strain and forms a peak extending between $6-8 \%$ of strain. As strain increases corresponding to a linearly increasing load, $\Delta R / R_{0}$ decreases linearly until $30-40 \%$ strain. At this point an extended local minimum is reached and any further increase in strain is followed by an increase in $\Delta R / R_{0}$. The unstable response for the $3 \% \mathrm{CNT}$ content is directly related to the mechanical response. The material exhibits a prolonged yielding region, which is reflected by the electrical measurements.

The dense foams exhibit a similar mechanical but a different electrical behaviour. For low mechanical load levels and strains below $4 \%$, the $\Delta R / R_{0}$ value increases linearly. From that point on, by increasing the strain, $\Delta R / R_{0}$ continues to increase by a different rate until almost $30 \%$. In the meantime stress continues to increase following a narrower slope. After that point the rate of increase of $\Delta R / R_{0}$ decreases further, but still attains an increasing trend. This holds true for the lower CNT contents studied. For the dense foam having $5 \mathrm{wt} \% \mathrm{CNT}$ (black lines), the mechanical performance seems to be poorer than the other CNT concentrations. This is evident by the low elastic modulus exhibited in the linear region and the overall lower stresses. Additionally, it is very interesting to note that this is also exhibited by the behaviour of $\Delta R / R_{0}$. The $\Delta R / R_{0}$ curves for the dense $5 \%$ foam samples resemble those of the light foam.

It is interesting to point out that for the cases where the transition of the mechanical response from the linear to the yielding plateau is not clearly expressed; the electrical response exhibits a peak. The transition can be identified by the change of the slope of the electrical curve from positive to negative. For the case where the mechanical transition from Stage I to Stage II is much clearer, the respective electrical curve exhibits a transition point where the positive slope decreases slightly.

Based on experimental indications, it can be said that the nano-filler content affects the sensitivity of the electrical response to mechanical stimulus. This can be observed by comparing the amount of change in electrical properties versus the amount of change in the mechanical response, which is expressed by the initial slope of the curves in Figure 7. The trend implies that the higher the CNT content the more sensitive the system is. This CNT loading-performance sensitivity has been reported in other sensing studies utilizing CNTs in polymer $[2,37]$ and in fibrous composites $[18,22,32]$. Furthermore, the contribution of the CNTs in sensing is expected to be expressed more in the elastic region rather than the yielding plateau. The reason for this is that crushing of the cells occurs at a higher scale level. Any influence at nano-scale would be shadowed. Nevertheless, the conductivity they offer to the nano-polymer system still remains. Therefore, it is believed that the influence of the CNT dispersion in the later stages of damage is much lower. As a matter of fact, their use is primarily for early sensing of damage.

The difference in the electrical response of dense foam with $5 \mathrm{wt} \%$ MWCNT and the other two nanofiller concentrations is attributed to the dispersion of the nano-fillers. The mechanical performance resembles that of light weight foam. At this high level of weight fraction, effective dispersion to achieve optimal distribution for mechanical performance is very challenging. Agglomerations are observed percolating to reach a conductive network through individually dispersed CNT. These agglomerations can act as stress raisers/concentration points. Considering the thinner cross-section (cell walls) available to transfer the compressive loads, the presence of agglomerations magnifies their effect.

\subsection{Non-dimensional electrical measurements as a function of stress state}

Having the aforementioned observations and diagrams as a basis, we attempt here to identify pattern behaviours, introduce the failure/damage mechanisms into perspective for sensing using electrical measurements and define key parameter for detecting the damage evolution in polymer foams.

Firstly, the recorded values are expressed in a nondimensional basis. The bulk volume resistivity of the foams is elaborated solving Equation (1) for the resistivity term. The stress values have already been calculated previously. To verify that the stress and electrical behaviour correlate, we plot the elaborated bulk volume resistivity against stress. Bulk 

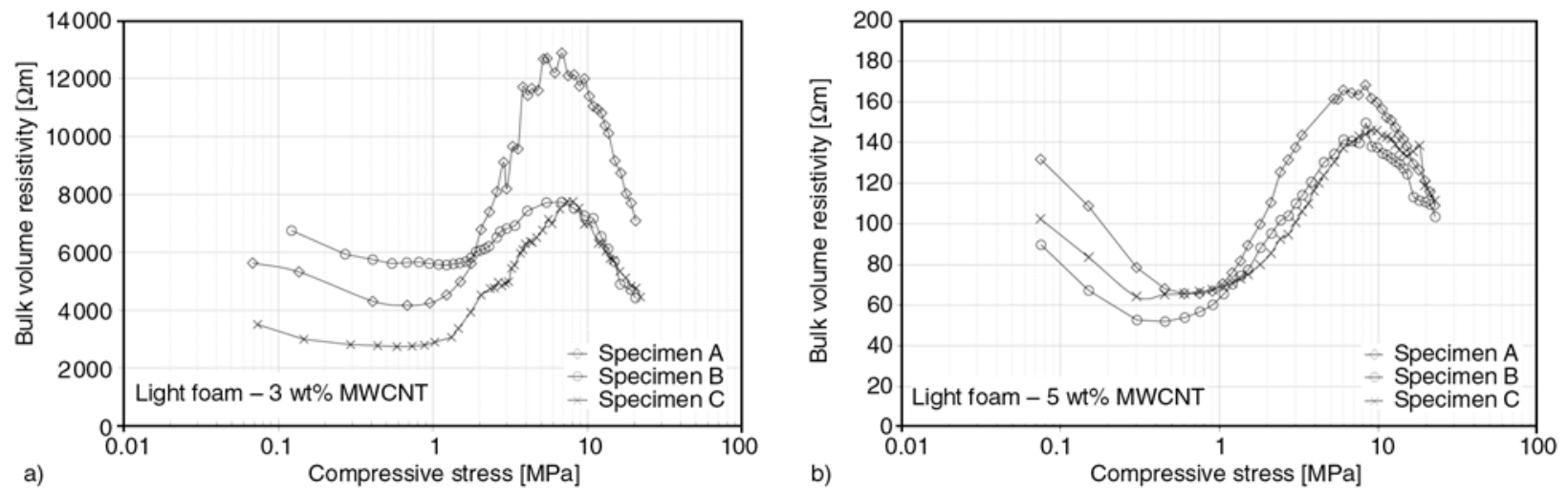

Figure 8. Bulk electrical property change Vs. stress for light foams: (a) $3 \mathrm{wt} \%$ and (b) $5 \mathrm{wt} \% \mathrm{MWCNT}$

volume resistivity takes into account the dimensional change of the specimens and thus is believed to convey clearer information on the state of the materials. A logarithmic scale is used for stress values to enhance the exhibited transitions between the variables. The resulting curves are shown in Figure 8 and 9 for the light and dense foam groups respectively.

To analyze and explain the observations of the electrical resistivity, the mechanisms involved in the deformation are revisited here, focusing on the failure of cellular solids under compression. Along the way, we assess the effect of these mechanisms on the electrical properties.

The mechanical response curve of foam under compression is characterized by three stages. Each reflects different micro-structural compliance and failure mechanisms. [36, 38-40]

As already mentioned, the first stage is the linearelastic response of the foam. During this stage, a number of deformation mechanisms occurs with the more dominant ones being the cell wall bending in combination with the compression of the gas contained within the closed foam cells. In this stage, stress increases linearly with deformation. The modulus exhibited depends on the density of the foam. In principle at this level of stress, strain is recoverable, hence is characterized as elastic. Nevertheless, experimental observations here and in other studies have a reported non-recoverable deformation already from this stage, attributed to statistical fracture of cells and localized stress concentrations. This is expected to be reflected by the electrical properties too. Damage in the microstructure is expected to interrupt the conductive paths and increase resistivity. Recoverable deformation is generally expected to recoverably decrease the electrical resistivity.
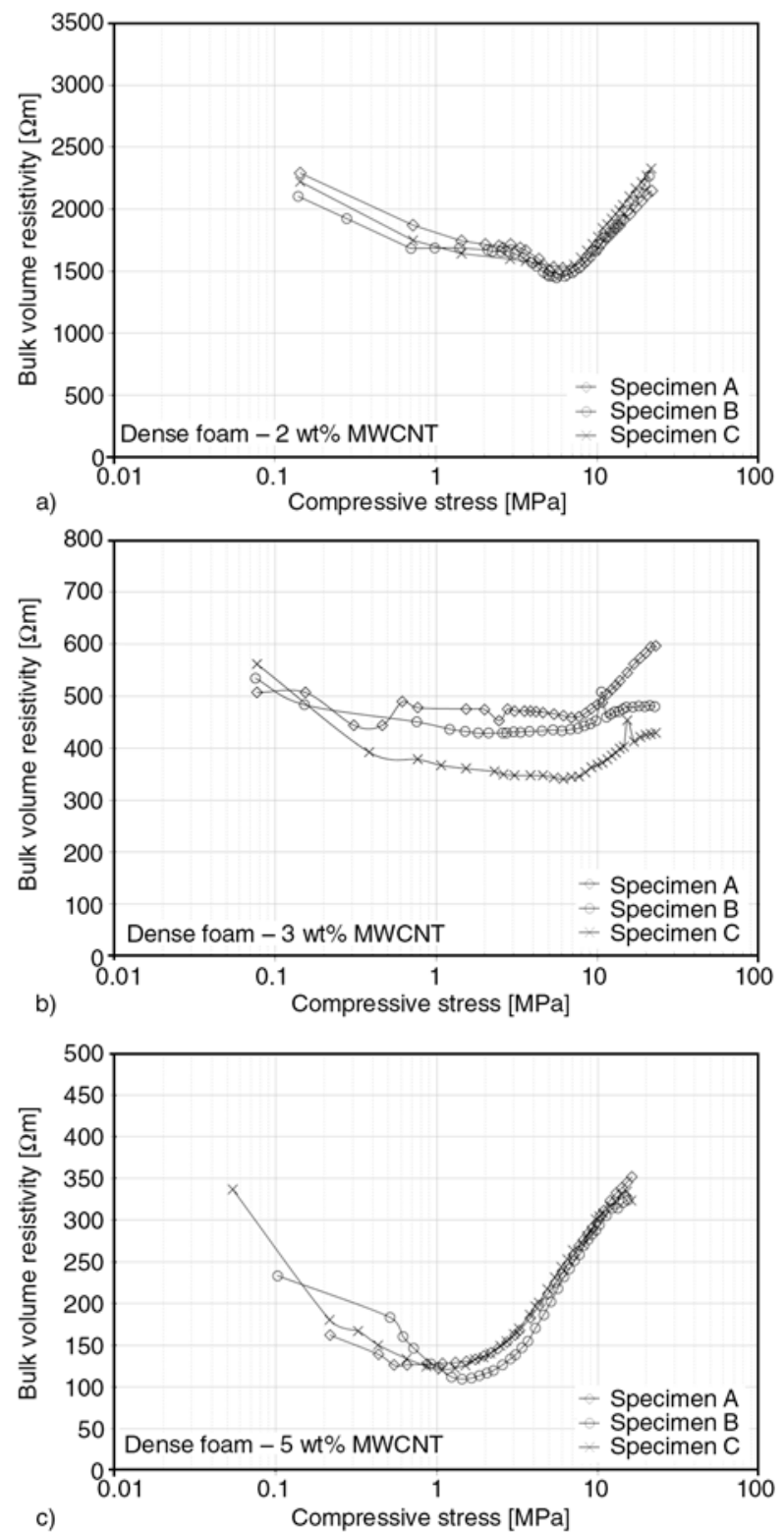

Figure 9. Bulk electrical property change Vs. stress for dense foams: (a) $2 \mathrm{wt} \%$, (b) $3 \mathrm{wt} \%$ and (c) $5 \mathrm{wt} \%$ MWCNT

This is attributed to the local re-arrangement of the CNT $[2,9]$ due to the compressive stresses. The CNT 
contacts increase and more conductive paths are available, decreasing the exhibited resistivity.

The second stage of ideally elastic-plastic foams is characterized by continued deformation at nearly constant stress, usually forming a plateau. During this stage, plastic yielding occurs and thus strain increases more rapidly than stress. The mechanisms associated with the yielding/collapse plateau, vary depending on the properties of the cell-walls. For rigid foams, macroscopic plastic yielding in the micro-structure is related to fracture of the walls due to buckling failure [39]. In compression, the failure behaviour of low-density foams is dominated by the early collapse of large porous cells which triggers macroscopic fracture of the specimen, whereas high-density foams exhibit more uniform deformation, which results in ductile-like fracture mode under quasi-static loading [41]. This results in the fracture of the material microstructure on the mechanical level. The fracture interrupts the continuity of the material and breaks the available conductive paths. Fractured cell walls are still in contact thus contributing to electrical conduction. However, resistivity now is higher because contact resistance is higher than conduction within the network. This is reflected by the increase of the bulk volume resistivity.

The final stage of stress-strain curve is the densification. At this stage, the stress rises steeply and the foam begins to respond as an increasingly compact solid. The cellular structure within the material has collapsed compacting in a lamellar microstructure. For further deformation compression of the solid material is required. Essentially, the resulting lamellae from the collapsed cells are compacted tightly. This mechanism increases the contact surface between the material formerly comprising the cell walls, providing larger paths for electrical conduction and thus decreased resistivity.

In the view of the above-said, for the light foams, the distinct stages are identified for both CNT concentrations. In Stage I, the bulk electrical resistivity is decreasing with the increase of the applied stress. The mechanical response of the foam is nearly linear in semi-log axis (Figure 8a). A minimum around $1 \mathrm{MPa}$ for the $3 \mathrm{wt} \% \mathrm{MWCNT}$ and $0.8-0.9 \mathrm{MPa}$ for the $5 \mathrm{wt} \%$ MWCNT is consistently observed for all the specimens. This point corresponds to nearly $10 \%$ compressive strain. In Stage II, resistivity increases (nearly 3-4 times) and it reaches a peak at a stress around 8-9 MPa. The stress is high enough to start causing larger scale cell fracture. This continues, as the stress increases further, more and more cells fracture up to a point where many cells have been destroyed. At this point the resistivity shows a maximum at around $9 \mathrm{MPa}$, which is the same for both nano-filler contents. This point corresponds to $55-65 \%$ strain. After this point the last stage starts where the resistivity decreases again until the end of the experiment. The broken sides of each cell start to touch and with the increased load they are pressed against each other. This leads to a better contact between the conductive cell walls and thus the decrease in resistivity.

For the dense foam, the behaviour is similar to the one described above (Figure 9). The two first stages are clearly identified. The transition from Stage I to Stage II corresponding to the minimum in resistivity is observed at the range of 7-8 MPa. For the high CNT content this point is around $1.1 \mathrm{MPa}$ (very close to the transition for light foams). The third characteristic stage is not observed as the experiment was stopped early in terms of stress (all loading curves reached a maximum of $20 \mathrm{MPa}$ ). As it is seen the applied load did not suffice to lead to the compression of the fractured walls. The trend of the curves however indicates a maximum to be expected close to $11-13 \mathrm{MPa}$, as previously described. It is believed that the bell-shaped exhibited by the light foams would be expressed if the compressive load extended further higher.

\subsection{Damage evolution sensed through electrical properties}

In this section, we attempt to illustrate the described information in a characteristic diagram for damage sensing through electrical properties. We introduce a sigmoid curve that incorporates the aforementioned observations and is based on the damage mechanisms involved (Figure 10). The $\mathrm{X}$-axis is the logarithmic compressive stress while the Y-axis is the elaborated bulk volume resistivity. The curve consists of three parts corresponding to the different stages of the mechanical response of the foams. The first stage giving a decrease in resistivity represents the elastic response in compression. The second stage corresponds to yielding with an increase of resistivity. The third stage showing a decrease in resistivity corresponds to the densification of the foam. The 


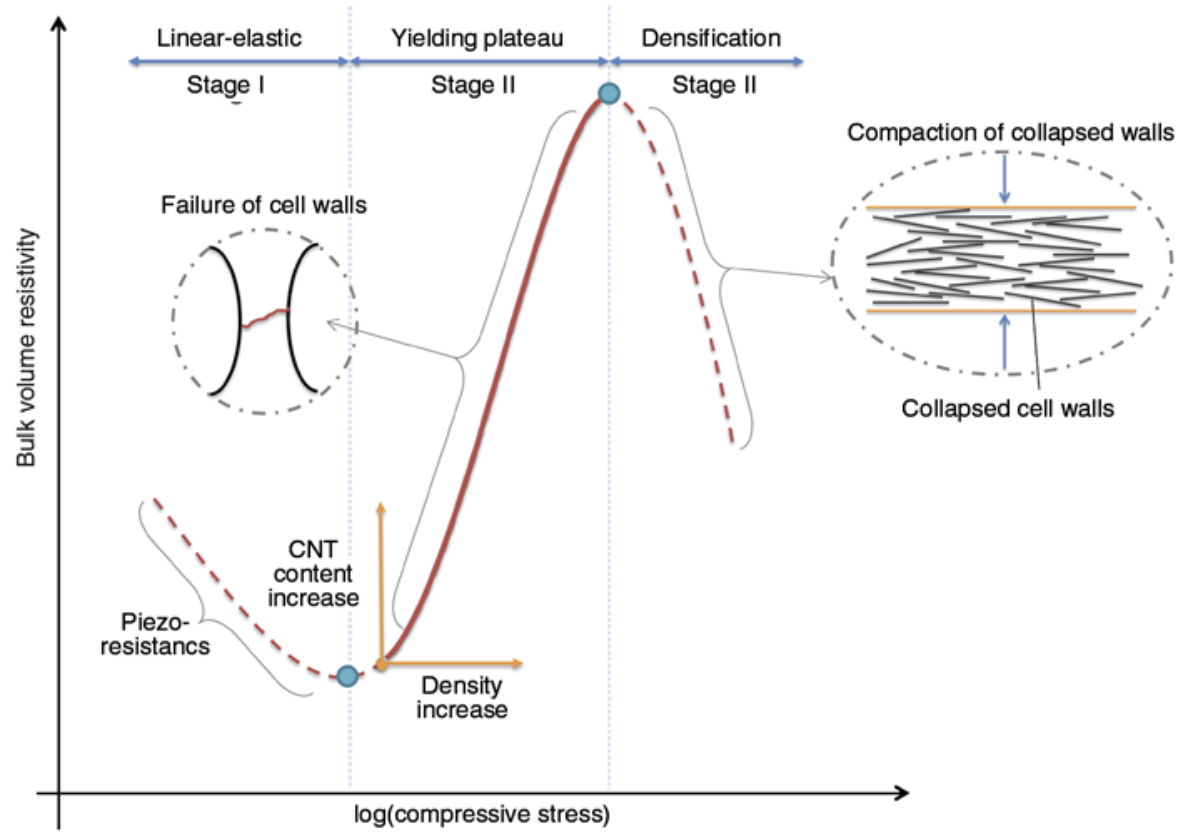

Figure 10. Damage evolution in foams sensed through electrical properties: qualitative electrical property change and involved damage mechanisms

proposed curve can be used for identifying the different damage stages of a foam.

Different conduction mechanisms are associated to each stage of the curve. Stage I is claimed to express the piezo-resistive part, as it exhibits the highest dependence on the MWCNT content. Stage II is dominated by the cell wall fracture, which effectively interrupts the conductive network by excluding large parts of it. Thus resistivity increase is expected. Stage III is believed to essentially express the compaction of the failed cell walls, which are conductive due to the CNT within the polymer. The proposed mechanism for Stage III (Figure 10 - right inset) is justified by SEM micrographs (Figure 11),

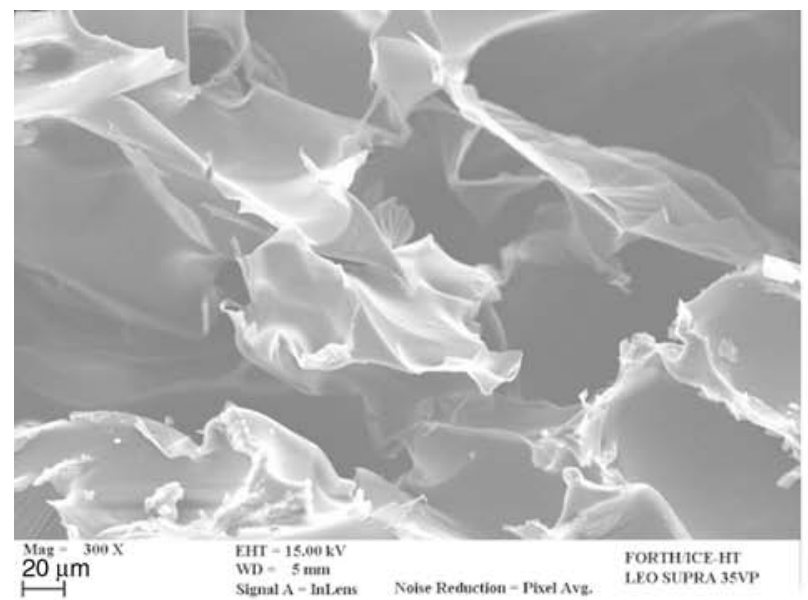

a) where the cell walls are visible in the form of flakes. Here the cell walls are shown in their form after compression and previous figures showed the CNT within the cell walls. Considering the situation reversely, it is expected that the compaction of these flakes leads to the electrical response (Figure 10). The effectiveness of CNT dispersion in the system is pre-dominantly affecting Stage I of the curve. In the later damage stages, micro- and macro-scale fracture shadows any effect of CNT dispersion. Fracture of the foam micro-structure breaks large parts of the conductive network and the only issue still contributing is the conductivity of the polymer struts and cell walls. Thus CNT dispersion seems to

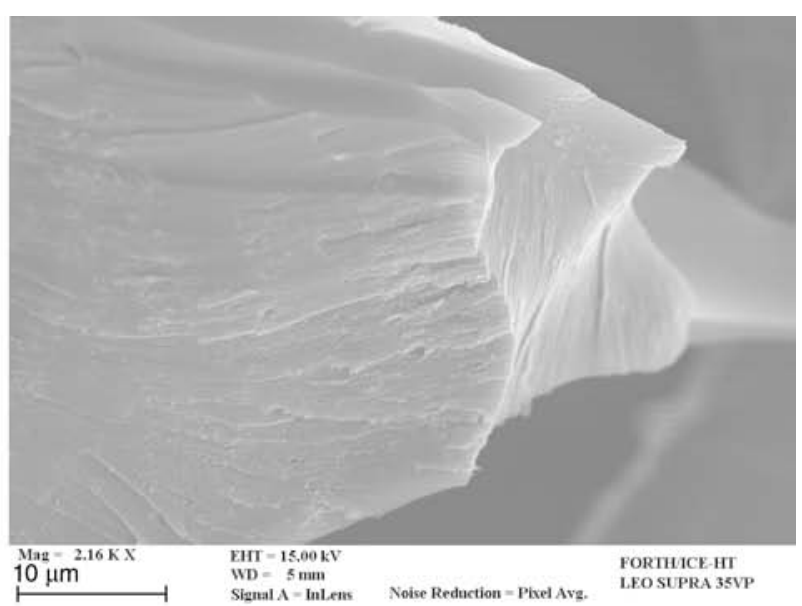

b)

Figure 11. SEM micrographs of the failed microstructure: (a) collapsed cell walls in the form of flakes, (b) close-up of MWCNT dispersion in the failed cross-section of the cell walls 
matter less at the later stages, as long as the CNTpolymer remains conductive.

Furthermore, it is believed that the exact location of the master-curve on the X-Y plane is defined by several parameters characterizing the material system. Two main parameters can already been identified; density and nano-filler content. Firstly, based on density the curve is shifted to the left for light foams, to the right for denser ones. This is based on the observation that for the dense foams the peak and Stage III decrease is not expressed up to the stress reached. It is believed that because cell walls are thicker in dense foams, they can withstand higher stresses. To this end, the peak value expressing 'saturation' of damaged cells and indicating the transition to Stage III may also shift to higher stresses. Secondly, from the experimental results it was seen that the nano-filler content controls the conductivity level of the foam and both the amount of the resistivity drop and the drop rate expressed in Stage I. Essentially, the level of conductivity shifts the curve on the vertical axis.

This diagram can serve as an initial attempt to formulate a cross-property relation for polymer foams $[26,30]$, but further experimental evidences are needed to quantify and standardize the findings to form a cross-property relation.

\section{Conclusions}

Electrically conductive PUR foams with varying levels of electrical conductivity were successfully prepared at various densities and using different MWCNT concentrations. MWCNT were dispersed in the polyol component of PUR using high shear mixing. From this base material, conductive foams having different densities were produced. The foams exhibited varying levels of DC electrical conductivity which have been related to nano-filler concentration and density in [10], laying the ground for this work.

Here, for the first time, the evolution of electrical properties of the foams during compressive loading until failure was investigated. Initial results are analysed and damage mechanisms are proposed to explain the observed performance. The recordings were consistent within the same material groups and the overall behaviour of electrical properties was repeatable and characteristic. Three different regions are observed in the diagram of the volume resistivity versus compressive load. The aforemen- tioned regions are correlated with the three discrete regions of the stress - strain curve of the foam. In the first region (linear elastic) the resistivity decreases as the compressive load increases while the second region (yielding plateau) due to breakage of the cells the volume resistivity increases. In the third region (densification) the volume resistivity decreases again because the collapsed cells are compacted tightly. Each stage is associated to a different mechanisms respectively; piezo-resistivity, micro-structure failure, compaction of failed microstructure.

The nano-phase dispersion controls the overall conductivity of the system and the sensitivity of the initial loading stage. The later stages are more related to macroscale damage of the structure thus masking any influence from the CNT dispersion; electrical conductivity of the polymer is only required. For denser foams, the technique may seem less efficient but it is believed that it is due to the bearing capability of the microstructure that this occurs.

In the range of CNTs content that we studied the electrical resistivity - stress curves a range of similarities exists. The above laid the grounds for establishing a damage evolution diagram for sensing through electrical properties illustrating the information collected. This diagram proved to be characteristic for the foams studied offering novel potential for the developed systems.

The information, mechanisms and formulations presented in this work may enable the development of dedicated advanced Non-Destructive Inspection techniques for foams and sandwich composite struc, as well as modelling attempts to express the aforementioned observations, especially in Stage II which represents the largest fraction of the materials life. Such techniques could enable on-line damage identification as well as production qualification and become part of novel more advanced monitoring systems [42]. As a matter of fact, similar techniques have demonstrated their suitability to offer prompt information particularly on the production progress of the 'packing' and 'gelation' stages of polymeric foams, otherwise not so easily possible [27].

\section{Acknowledgements}

This work was supported by the 'Innovative Action for Plastics and Composites' of the Regional Innovation Pole of Western Greece. The authors would like to thank Mrs. Myrto Matzakou for her contribution in the preparation of the materials as well as her support in the experimental work. 


\section{References}

[1] Du J-H., Bai J., Cheng H-M.: The present status and key problems of carbon nanotube based polymer composites. Express Polymer Letters, 1, 253-273 (2007). DOI: 10.3144/expresspolymlett.2007.39

[2] Karapappas P., Tsotra P., Scobbie K.: Effect of nanofillers on the properties of a state of the art epoxy gelcoat. Express Polymer Letters, 5, 218-227 (2011). DOI: 10.3144/expresspolymlett.2011.21

[3] Rizvi R., Kim J-K., Naguib H.: Synthesis and characterization of novel low density polyethylene-multiwall carbon nanotube porous composites. Smart Materials and Structures, 18, 104002/1-104002/10 (2009). DOI: 10.1088/0964-1726/18/10/104002

[4] Yang Y., Gupta M. C., Dudley K. L., Lawrence R. W.: Conductive carbon nanofiber-polymer foam structures. Advanced Materials, 17, 1999-2003 (2005). DOI: $10.1002 /$ adma.200500615

[5] Xu X-B., Li Z-M., Shi L., Bian X-C., Xiang Z-D.: Ultralight conductive carbon-nanotube-polymer composite. Small, 3, 408-411 (2007).

DOI: $10.1002 / \mathrm{smll} .200600348$

[6] Harikrishnan G., Singh S. N., Kiesel E., Macosko C. W.: Nanodispersions of carbon nanofiber for polyurethane foaming. Polymer, 51, 3349-3353 (2010). DOI: 10.1016/j.polymer.2010.05.017

[7] Antunes M., Mudarra M., Velasco J. I.: Broad-band electrical conductivity of carbon nanofibre-reinforced polypropylene foams. Carbon, 49, 708-711 (2011). DOI: $10.1016 /$ j.carbon.2010.10.032

[8] Yan D-X., Dai K., Xiang Z-D., Li Z-M., Ji X., Zhang W-Q.: Electrical conductivity and major mechanical and thermal properties of carbon nanotube-filled polyurethane foams. Journal of Applied Polymer Science, 120, 3014-3019 (2011).

DOI: $10.1002 / a p p .33437$

[9] Xiang Z-D., Chen T., Li Z-M., Bian X-C.: Negative temperature coefficient of resistivity in lightweight conductive carbon nanotube/polymer composites. Macromolecular Materials and Engineering, 294, 9195 (2009).

DOI: $10.1002 /$ mame.200800273

[10] Athanasopoulos N., Baltopoulos A., Matzakou M., Vavouliotis A., Kostopoulos V.: Electrical conductivity of polyurethane/MWCNT nanocomposite foams. Polymer Composites, 33, 1302-1312 (2012). DOI: $10.1002 / p c .22256$

[11] Chung D. D. L.: Self-monitoring structural materials. Materials Science and Engineering R: Reports, 22, 5778 (1998).

DOI: $10.1016 / \mathrm{S} 0927-796 X(97) 00021-1$

[12] Rizvi R., Cochrane B., Biddiss E., Naguib H.: Piezoresistance characterization of poly(dimethyl-siloxane) and poly(ethylene) carbon nanotube composites. Smart Materials and Structures, 20, 094003/1-094003/9 (2011). DOI: $10.1088 / 0964-1726 / 20 / 9 / 094003$
[13] Wichmann M. H. G., Buschhorn S. T., Gehrmann J., Schulte K.: Piezoresistive response of epoxy composites with carbon nanoparticles under tensile load. Physical Review B, 80, 245437/1-245437/8 (2009). DOI: $10.1103 /$ PhysRevB.80.245437

[14] Wichmann M. H. G., Buschhorn S. T., Böger L., Adelung R., Schulte K.: Direction sensitive bending sensors based on multi-wall carbon nanotube/epoxy nanocomposites. Nanotechnology, 19, 475503/1475503/5 (2008).

DOI: $10.1088 / 0957-4484 / 19 / 47 / 475503$

[15] Wang L., Wang X., Li Y.: Relation between repeated uniaxial compressive pressure and electrical resistance of carbon nanotube filled silicone rubber composite. Composites Part A: Applied Science and Manufacturing, 43, 268-274 (2012).

DOI: 10.1016/j.compositesa.2011.10.017

[16] Park J-M., Kim P-G., Jang J-H., Wang Z., Kim J-W., Lee W-I., Park J-G., DeVries L. K.: Self-sensing and dispersive evaluation of single carbon fiber/carbon nanotube (CNT)-epoxy composites using electromicromechanical technique and nondestructive acoustic emission. Composites Part B: Engineering, 39, 11701182 (2008).

DOI: 10.1016/j.compositesb.2008.03.004

[17] Abry J. C., Choi Y. K., Chateauminos A., Dalloz B., Giraud G., Salvia M.: In-situ monitoring of damage in CFRP laminates by means of AC and DC measurements. Composites Science and Technology, 61, 855864 (2001).

DOI: $10.1016 / \mathrm{S} 0266-3538(00) 00181-0$

[18] Kostopoulos V., Vavouliotis A., Karapappas P., Tsotra P., Paipetis A.: Damage monitoring of carbon fiber reinforced laminates using resistance measurements. Improving sensitivity using carbon nanotube doped epoxy matrix system. Journal of Intelligent Material Systems and Structures, 20, 1025-1034 (2009).

DOI: $10.1177 / 1045389 X 08099993$

[19] Nofar M., Hoa S. V., Pugh M. D.: Failure detection and monitoring in polymer matrix composites subjected to static and dynamic loads using carbon nanotube networks. Composites Science and Technology, 69, 1599-1606 (2009).

DOI: 10.1016/j.compscitech.2009.03.010

[20] Vavouliotis A., Paipetis A., Kostopoulos V.: On the fatigue life prediction of CFRP laminates using the electrical resistance change method. Composites Science and Technology, 71, 630-642 (2011). DOI: 10.1016/j.compscitech.2011.01.003

[21] Sotiriadis G., Tsotra P., Paipetis A., Kostopoulos V.: Stiffness degradation monitoring of carbon nanotube doped glass/vinylester composites via resistance measurements. Journal of Nanostructured Polymers and Nanocomposites, 3, 90-95 (2007). 
[22] Böger L., Wichmann M. H. G., Meyer L. O., Schulte $\mathrm{K}$.: Load and health monitoring in glass fibre reinforced composites with an electrically conductive nanocomposite epoxy matrix. Composites Science and Technology, 68, 1886-1894 (2008).

DOI: $10.1016 /$ j.compscitech.2008.01.001

[23] Gao L., Thostenson E. T., Zhang Z., Chou T-W.: Coupled carbon nanotube network and acoustic emission monitoring for sensing of damage development in composites. Carbon, 47, 1381-1388 (2009).

DOI: $10.1016 /$ j.carbon.2009.01.030

[24] Baltopoulos A., Kostopoulos V., Pambaguian L.: Sensing capabilities of multifunctional composite materials using carbon nanotubes. in ' $61^{\text {st }}$ International Astronautical Congress 2010 (IAC 2010), Prague, Czech Republic' Vol 13, 11004-11012 (2010).

[25] Ortona A., D’Angelo C., Bianchi G.: Monitoring sandwich structured $\mathrm{SiC}$ ceramics integrity with electrical resistance. NDT\&E International, 46, 77-82 (2012). DOI: $10.1016 /$ j.ndteint.2011.11.007

[26] Sevostianov I., Kováik J., Simaník F.: Correlation between elastic and electric properties for metal foams: Theory and experiment. International Journal of Fracture, 114, 23-28 (2002).

DOI: 10.1023/A:1022674130262

[27] Torres-Sánchez C., Corney J.: Identification of formation stages in a polymeric foam customised by sonication via electrical resistivity measurements. Journal of Polymer Research, 16, 461-470 (2009). DOI: $10.1007 / \mathrm{s} 10965-008-9249-4$

[28] Hutzler S., Verbist G., Weaire D., van der Steen J. A: Measurement of foam density profiles using AC capacitance. Europhysics Letters, 31, 497-502 (1995). DOI: $10.1209 / 0295-5075 / 31 / 8 / 013$

[29] Brady S., Diamond D., Lau K-T.: Inherently conducting polymer modified polyurethane smart foam for pressure sensing. Sensors and Actuators A: Physical, 119, 398-404 (2005). DOI: $\underline{10.1016 / \mathrm{j} . \text { sna.2004.10.020 }}$

[30] Kim A., Hasan M. A., Nahm S. H., Cho S. S.: Evaluation of compressive mechanical properties of Alfoams using electrical conductivity. Composite Structures, 71, 191-198 (2005).

DOI: $\underline{10.1016 / j . c o m p s t r u c t .2004 .10 .016}$

[31] Vavouliotis A., Fiamegou E., Karapappas P., Psarras G. C., Kostopoulos V.: DC and AC conductivity in epoxy resin/multiwall carbon nanotubes percolative system. Polymer Composites, 31, 1874-1880 (2010). DOI: $10.1002 / p c .20981$

[32] Vavouliotis A., Karapappas P., Loutas T., Voyatzi T., Paipetis A., Kostopoulos V.: Multistage fatigue life monitoring on carbon fibre reinforced polymers enhanced with multiwall carbon nanotubes. Plastics, Rubber and Composites, 38, 124-130 (2009). DOI: $10.1179 / 174328909 X 387928$
[33] Huang Y. Y., Terentjev E. M.: Dispersion of carbon nanotubes: Mixing, sonication, stabilization, and composite properties. Polymers, 4, 275-295 (2012).

DOI: $10.3390 /$ polym 4010275

[34] Yan D., Xu L., Chen C., Tang J., Ji X., Li Z.: Enhanced mechanical and thermal properties of rigid polyurethane foam composites containing graphene nanosheets and carbon nanotubes. Polymer International, 61, 11071114 (2012). DOI: $10.1002 /$ pi.4188

[35] Saha M. C., Kabir Md. E., Jeelani S.: Enhancement in thermal and mechanical properties of polyurethane foam infused with nanoparticles. Materials Science and Engineering A, 479, 213-222 (2008).

DOI: $10.1016 /$ j.msea.2007.06.060

[36] Rusch K. C.: Load-compression behavior of brittle foams. Journal of Applied Polymer Science, 14, $1263-$ 1273 (1970).

DOI: 10.1002/app.1970.070140514

[37] Ku-Herrera J. J., Avilés F.: Cyclic tension and compression piezoresistivity of carbon nanotube/vinyl ester composites in the elastic and plastic regimes. Carbon, 50, 2592-2598 (2012).

DOI: $10.1016 /$ j.carbon.2012.02.018

[38] Gibson L. J., Ashby M. F.: Cellular solids: Structure and properties (second edition). Cambridge University Press, Cambridge (1997).

[39] Deschanel S., Vanel L., Godin N., Maire E., Vigier G., Ciliberto S.: Mechanical response and fracture dynamics of polymeric foams. Journal of Physics D: Applied Physics, 42, 214001/1-214001/14 (2009).

DOI: $10.1088 / 0022-3727 / 42 / 21 / 214001$

[40] Rusch K. C.: Energy-absorbing characteristics of foamed polymers. Journal of Applied Polymer Science, 14, 1433-1447 (1970).

DOI: 10.1002/app.1970.070140603

[41] Zhang J., Lin Z., Wong A., Kikuchi N., Li V. C., Yee A. F., Nusholtz G. S.: Constitutive modeling and material characterization of polymeric foams. Journal of Engineering Materials and Technology, 119, 284-291 (1997).

DOI: $10.1115 / 1.2812258$

[42] Baltopoulos A., Vavouliotis A., Kostopoulos V., Polydorides N., Pambaguian L.: Electrical tomography as a tool for non-destructive assessment of composite structures. in 'Emerging technologies in non-destructive testing V' (eds.: Paipetis A. S., Matikas T. E., Aggelis D. G., Van Hemelrijck D.) CRC Press, Boca Raton, 389-394 (2012). DOI: $10.1201 / \mathrm{b} 11837-70$ 